\title{
Interspecific Hybridization between Eggplant and Wild Relatives from Different Genepools
}

\author{
Mariola Plazas, Santiago Vilanova, Pietro Gramazio, Adrián Rodríguez-Burruezo, Ana Fita, \\ and Francisco J. Herraiz \\ Instituto de Conservación y Mejora de la Agrodiversidad Valenciana, Universitat Politècnica de \\ València, Camino de Vera 14, 46022 València, Spain
}

Rajakapasha Ranil and Ramya Fonseka

Department of Crop Science, Faculty of Agriculture, University of Peradeniya, Old Galaha Road, Peradeniya 20400, Sri Lanka

Lahiru Niran

Agriculture Research Station, Girandurukotte 90750, Sri Lanka

Hemal Fonseka

Horticultural Crop Research and Development Institute, Gannowura Road, Peradeniya 20400,

Sri Lanka

Brice Kouassi, Abou Kouassi, and Auguste Kouassi

Laboratory of Genetics, Félix Houphouët-Boigny University, 01 BP V 34, Abidjan 01, Ivory Coast

Jaime Prohens ${ }^{1}$

Instituto de Conservación y Mejora de la Agrodiversidad Valenciana, Universitat Politècnica de

València, Camino de Vera 14, 46022 València, Spain

Additional Index words. breeding, fruit set, germination, introgression, markers, Solanum melongena

\begin{abstract}
Wild relatives represent a source of variation for many traits of interest for eggplant (Solanum melongena) breeding, as well as for broadening the genetic base of this crop. However, interspecific hybridization with wild relatives has been barely used in eggplant breeding programs. As initiation of an introgression breeding program we performed 1424 interspecific hybridizations between six accessions of eggplant from the Occidental and Oriental groups and 19 accessions of 12 wild species from the primary (Solanum incanum and Solanum insanum), secondary (Solanum anguivi, Solanum dasyphyllum, Solanum lichtensteinii, Solanum linnaeanum, Solanum pyracanthos, Solanum tomentosum, and Solanum violaceum), and tertiary (Solanum elaeagnifolium, Solanum sisymbriifolium, and Solanum torvum) genepools. Fruit set, hybrid seed, and seed germination were obtained between Solanum melongena and all wild species of the primary and secondary genepools. The highest fruit set percentage and quantity of seeds per fruit were obtained with the two primary genepool species $S$. incanum and $S$. insanum as well as with some secondary genepool species, like $S$. anguivi, $S$. dasyphyllum, or $S$. lichtensteinii, although some differences among species were observed depending on the direction of the hybridization. For small-fruited wild species, the number of seeds per fruit was lower when using them as maternal parent. Regarding tertiary genepool species, fruit set was obtained only in interspecific hybridizations of eggplant with $S$. sisymbriifolium and $S$. torvum, although the fruit of the former were parthenocarpic. However, it was possible to rescue viable interspecific hybrids with S. torvum. In total we obtained 58 interspecific hybrid combinations (excluding reciprocals) between eggplant and wild relatives. Some differences were observed among $S$. melongena accessions in the degree of success of interspecific hybridization, so that the number of hybrid combinations obtained for each accession ranged between 7 (MEL2) and 16 (MEL1). Hybridity of putative interspecific hybrid plantlets was confirmed with a morphological trait (leaf prickliness) and 12 single nucleotide polymorphism markers. The results show that eggplant is amenable to interspecific hybridization with a large number of wild species, including tertiary genepool materials. These hybrid materials are the starting point for introgression breeding in eggplant and in some cases might also be useful as rootstocks for eggplant grafting.
\end{abstract}

\footnotetext{
Received for publication 14 Aug. 2015. Accepted for publication 15 Oct. 2015 This work was undertaken as part of the initiative "Adapting Agriculture to Climate Change: Collecting, Protecting and Preparing Crop Wild Relatives," which is supported by the Government of Norway. The project is managed by the Global Crop Diversity Trust with the Millennium Seed Bank of the Royal Botanic Gardens, Kew and implemented in partnership with national and international gene banks and plant breeding institutes around the world. For further information, see the project website: http://www.cwrdiversity.org/. Pietro Gramazio is grateful to Universitat Politècnica de Valencia for a predoctoral (Programa FPI de la UPV-Subprograma 1/2013 call) contract.

${ }^{1}$ Corresponding author. E-mail: jprohens@btc.upv.es.
}

Eggplant ranks as the sixth vegetable crop, after tomato (Solanum lycopersicum), watermelon (Citrullus lanatus), onion (Allium cepa), cabbage (Brassica oleracea var. capitata), and cucumber (Cucumis sativus), in global production with 49.4 million tonnes produced in 2013 (Food and Agriculture Organization of the United Nations, 2015). Eggplant is a staple food in many tropical and subtropical countries, being one of the 35 crops judged to be most important for food security and as such is included in the Annex 1 of the International Treaty on Plant 
Genetic Resources for Food and Agriculture (Fowler et al., 2003).

As occurs with many other domesticates, eggplant has a narrow genetic base, in particular modern $\mathrm{F}_{1}$ hybrid cultivars used for greenhouse cultivation (Muñoz-Falcón et al., 2009). Eggplant wild relatives have much higher genetic diversity than the cultivated species (Mutegi et al., 2015; Vorontsova et al., 2013; Weese and Bohs, 2010), and they represent sources of variation for resistance to traits of interest for eggplant breeding (Daunay and Hazra, 2012). For example, eggplant wild relatives grow in a wide range of conditions, including extreme conditions, like desert areas, environments with wide ranges of temperatures including night temperatures below $0{ }^{\circ} \mathrm{C}$, waterlogged and swampy areas, etc. (Davidar et al., 2015; Knapp et al., 2013; Lester et al., 2011). Because of their tolerance to abiotic and biotic stresses, eggplant wild relatives have been used for eggplant grafting (Gisbert et al., 2011b). Given that eggplant wild relatives can be found in a much wider range of environmental conditions than those of cultivated eggplant, these wild relatives could play a major role in breeding eggplants for adaptation to climatic change, which is a problem of great concern in many developing countries (Dempewolf et al., 2014). Also, some wild relatives present high contents of phenolic acids that are of interest for developing new eggplant cultivars with improved bioactive properties (Plazas et al., 2014b; Prohens et al., 2013). However, contrary to other important vegetable crops, like tomato (Díez and Nuez, 2008; Hajjar and Hodgkin, 2007), the use of wild relatives in eggplant breeding has been very limited (Daunay and Hazra, 2012; Rotino et al., 2014), and no commercial cultivars containing introgressions from wild-related species are known to us.

Depending on phylogenetic relationships and crossability with eggplant, wild relatives are considered as belonging to the primary, secondary, or tertiary genepools (Harlan and de Wet, 1971). The primary genepool is constituted by only two species, $S$. incanum and $S$. insanum, which provide fertile hybrids with eggplant (Davidar et al., 2015; Knapp et al., 2013). Solanum incanum grows in desert environments in the Middle East and North Africa and is tolerant to drought, while $S$. insanum is considered as the ancestor of eggplant (Meyer et al., 2012). Both species are phylogenetically the closest to the cultivated eggplant and are part of the "eggplant clade" (Davidar et al., 2015; Knapp et al., 2013; Mutegi et al., 2015; Vorontsova et al., 2013; Weese and Bohs, 2010). The secondary genepool is made up of a group of African and Southeast Asian "spiny" species of Solanum (Vorontsova et al., 2013; Weese and Bohs, 2010), which yield hybrids with different degrees of fertility when they are hybridized with eggplant (Daunay and Hazra, 2012; Rotino et al., 2014). Secondary genepool materials of special interest for eggplant breeding include species from: 1) the closely related "eggplant clade," like Solanum campylacanthum, S. lichtensteinii, and S. linnaeanum; 2) the sister "anguivi grade," like $S$. anguivi and $S$. dasyphyllum, which, respectively, are the wild ancestors of cultivated scarlet (Solanum aethiopicum) and gboma (Solanum macrocarpon) eggplants (Plazas et al., 2014a), the Canary Islands endemisms Solanum lidii and Solanum vespertilio (Prohens et al., 2007), S. violaceum and Solanum tomentosum; and 3) the more distant "Madagascar clade," like S. pyracanthos (Vorontsova et al., 2013). These secondary genepool species are of interest for breeding as this group is genetically very diverse and within it there is a wide diversity in tolerance to abiotic stresses, resistance to pests and diseases, as well as for fruit size, shape, and composition (Daunay and Hazra, 2012; Plazas et al., 2014a, 2014b; Prohens et al., 2013; Vorontsova et al., 2013). Finally, the tertiary genepool is an admixture of species from subgenus Leptostemonum, including species from the Old World as well as from the New World, with which occasionally it may be possible to obtain sterile or low fertility hybrids after embryo rescue or somatic hybridization (Daunay and Hazra, 2012; Rotino et al., 2014). Among these tertiary genepool species, $S$. torvum and S. sisymbriifolium are of great interest for breeding, given its resistance to multiple diseases (Bletsos et al., 2003; Gousset et al., 2005). Also, S. elaeagnifolium, an invasive weed with high tolerance to drought (Christodoulakis et al., 2009) may represent a genetic resource of interest for eggplant breeding.

An important issue in interspecific hybridization is the direction of the cross, as this may affect its rate of success, the number of seeds produced, as well as the dormancy of the seeds due to maternal effects (Morgan et al., 2010). In this respect, using $S$. melongena as the female parent is usually preferred, as it allows the recovery in the first generation of the $S$. melongena cytoplasm. This avoids potential sterility problems in backcross generations due to alloplasmy, which has been observed in eggplant lines containing the $S$. anguivi or $S$. violaceum cytoplasms (Isshiki and Kawajiri, 2002; Khan and Isshiki, 2011). Also, $S$. melongena fruit have more seeds than small-fruited wild species (Isshiki and Kawajiri, 2002) and in consequence, theoretically it is possible to obtain more seeds per cross when using $S$. melongena as a female parent. Finally, seeds extracted from $S$. melongena fruit either do not have dormancy or have a weak dormancy, whereas seeds from fruit of wild species may have a strong dormancy, which may hamper germination (Gisbert et al., 2011a).

Although previous reports exist on hybridization of eggplant with related species, which have provided useful data on crossability between eggplant and wild relatives (Behera and Singh, 2002; Daunay and Hazra, 2012; Davidar et al., 2015; Devi et al., 2015; Lester and Kang, 1998; Rotino et al., 2014), there are no interspecific hybridization studies involving several $S$. melongena accessions and a large number of wild accessions from different genepools including comprehensive quantitative data of fruit set, seed yield, and germination, as well as hybridity confirmation. Our objective was to obtain interspecific eggplant hybrids with a wide range of wild relatives of eggplant, as well as to obtain information on the relative efficiency of hybridization of eggplant with related species belonging to different genepools. Although the cultivated $S$. aethiopicum and $S$. macrocarpon might be of interest for common eggplant breeding (Prohens et al., 2012; Schaff et al., 1982), our work has focused on wild species, which genetically are more diverse than the cultivated species (Mutegi et al., 2015). All this information will be of interest for eggplant breeding aimed at introgression breeding as well as on the feasibility of using eggplant wild relatives for developing interspecific hybrid rootstocks.

\section{Materials and Methods}

Plant material. Six S. melongena accessions, of which three originated from Ivory Coast (MEL1 to MEL3) and three from Sri Lanka (MEL4 to MEL6) (Table 1) were used as cultivated $S$. melongena parentals. These accessions represent the diversity of landraces from the Occidental and Oriental 
Table 1. Materials of cultivated eggplant and wild relatives used for the hybridization experiments. The wild relatives are classified according to the cultivated eggplant genepool to which they belong.

\begin{tabular}{|c|c|c|c|}
\hline Species & Accession & $\begin{array}{c}\text { Accession code in } \\
\text { germplasm collection }\end{array}$ & Country of origin \\
\hline \multicolumn{4}{|l|}{ Cultivated eggplant } \\
\hline \multirow[t]{6}{*}{ Solanum melongena } & MEL1 & BBS-118/B & Ivory Coast \\
\hline & MEL2 & BBS-146 & Ivory Coast \\
\hline & MEL3 & BBS-175 & Ivory Coast \\
\hline & MEL4 & 07145 & Sri Lanka \\
\hline & MEL5 & 8104 & Sri Lanka \\
\hline & MEL6 & Ampara & Sri Lanka \\
\hline \multicolumn{4}{|l|}{ Primary genepool } \\
\hline Solanum incanum & INC1 & MM664 & Israel \\
\hline \multirow[t]{3}{*}{ Solanum insanum } & INS1 & SLKINS-1 & Sri Lanka \\
\hline & INS2 & SLKINS-1 & Sri Lanka \\
\hline & INS3 & MM498 & Japan \\
\hline \multicolumn{4}{|l|}{ Secondary genepool } \\
\hline \multirow[t]{2}{*}{ Solanum anguivi } & ANG1 & BBS119 & Ivory Coast \\
\hline & ANG2 & BBS125/B & Ivory Coast \\
\hline Solanum dasyphyllum & DAS1 & MM1153 & Uganda \\
\hline \multirow[t]{2}{*}{ Solanum lichtensteinii } & LIC1 & MM674 & South Africa \\
\hline & LIC2 & MM677 & Iran \\
\hline \multirow[t]{2}{*}{ Solanum linnaeanum } & LIN1 & JPT0028 & Spain \\
\hline & LIN3 & MM195 & Tunisia \\
\hline Solanum pyracanthos & PYR1 & SOLN-66 & Unknown \\
\hline Solanum tomentosum & TOM1 & MM992 & South Africa \\
\hline Solanum violaceum & VIO1 & SLKVIL-1 & Sri Lanka \\
\hline \multicolumn{4}{|l|}{ Tertiary genepool } \\
\hline Solanum elaeagnifolium & ELE1 & MM1627 & Senegal \\
\hline \multirow[t]{2}{*}{ Solanum sisymbriifolium } & SIS1 & SOLN-78 & Unknown \\
\hline & SIS2 & 1180 & Unknown \\
\hline \multirow[t]{2}{*}{ Solanum torvum } & TOR2 & SLKTOR-2 & Sri Lanka \\
\hline & TOR3 & 55953 & Unknown \\
\hline
\end{tabular}

${ }^{\mathrm{z}}$ Accessions with MM codes originate from the Institut National de Recherche Agronomique (INRA, Avignon, France) genebank (genebank code FRA030); the rest of accessions belong to the COMAV germplasm collection (Universitat Politècnica de València, Valencia, Spain).

2015), and the results of hybridizations between $S$. melongena and $S$. insanum can be considered as a control for fully cross compatible hybridizations.

Plant CULTIVATION AND HYBRIDIZATIONS. Seedlings of each accession were transplanted to a pollinator-free greenhouse in Valencia (Spain) in Apr. 2014, with at least 15 plants for each of the cultivated $S$. melongena accessions and at least 5 plants for each of the wild accessions. Hybridizations were made from June 2014 to Oct. 2014. For S. torvum, which is a short-day plant (Bletsos et al., 1998), hybridizations were performed during September and October only. Reciprocal hybridizations were performed, although priority was given to crossings in which $S$. melongena was used as female parent. For hybridization, flower buds before anthesis were emasculated and pollen of the male parent was deposited on a crystal slide and gently applied by rubbing over the stigma of the emasculated flower. Emasculations and hybridizations were made in the morning, avoiding the hours of higher temperatures. Female flowers were tagged and a record was kept of the hybridizations made for calculation of the percentage of fruit set.

SEED AND EMBRyo EXTRACTION AND GERMINATION. Fruit involving hybridizations of $S$. melongena with

eggplant groups (Cericola et al., 2013; Vilanova et al., 2012) and include accessions with different fruit colors, shapes, and sizes.

A total of 35 accessions corresponding to 15 wild species: 2 from the primary pool ( $S$. incanum and $S$. insanum), 10 from the secondary genepool ( $S$. anguivi, S. campylacanthum, S. dasyphyllum, S. lichtensteinii, S. lidii, S. linnaeanum, S. pyracanthos, $S$. tomentosum, $S$. vespertilio, and $S$. violaceum), and 3 from the tertiary genepool ( $S$. elaeagnifolium, $S$. sisymbriifolium and $S$. torvum) were initially considered. Seeds of these accessions are available from the germplasm bank of COMAV at Universitat Politècnica de València (Valencia, Spain). Seeds were soaked for $1 \mathrm{~d}$ in a gibberellic acid $\left(\mathrm{GA}_{3}\right)$ solution $(500$ $\left.\mathrm{mg} \cdot \mathrm{L}^{-1}\right)$ and germinated in petri dishes on a layer of $0.5 \mathrm{~cm}$ of embedded hydrophilic cotton covered by filter paper. However, nine accessions did not germinate, and plants of accessions of $S$. campylacanthum, $S$. lidii, and $S$. vespertilio had a slow development and very delayed or no flowering compared with the cultivated $S$. melongena. Therefore, the hybridization experiments reported here involve 19 accessions of 12 wild species (Table 1). Given that $S$. insanum, which was formerly considered as a botanical variety of $S$. melongena (Knapp et al., 2013), is fully cross compatible with $S$. melongena (Davidar et al., wild species from the primary and secondary genepools were harvested at physiological maturity and seeds manually extracted in the laboratory. Seeds extracted from individual fruit were placed on filter paper and allowed to dry under laboratory conditions and weighted. A sample of hybrid seed (at least 20 seeds, when available) for each of the hybrid combinations among the six S. melongena accessions and the 19 wild accessions for which seed was obtained was germinated using the protocol mentioned above and evaluated for germination. Germinated seeds were transplanted to plastic pots with growing substrate. Average values and sEs for seed weight and germination were calculated.

Fruit obtained by the crossing with tertiary genepool species were harvested after 15 to $30 \mathrm{~d}$ after pollination. Fruit were brought to the laboratory, where they were washed and surface sterilized with ethanol (96\%) under laminar flow cabinet conditions. Embryos were extracted and cultivated as indicated in Manzur et al. (2013). Basically, immature seeds were extracted and excised embryos were cultured in petri dishes containing half-strength Murashige and Skoog (MS) medium (with vitamins) supplemented with agar $\left(7 \mathrm{~g} \cdot \mathrm{L}^{-1}\right)$, sucrose $(40$ $\left.\mathrm{g} \cdot \mathrm{L}^{-1}\right)$, indole-3-acetic acid $\left(0.01 \mathrm{mg} \cdot \mathrm{L}^{-1}\right)$, and $\mathrm{GA}_{3}(0.01$ $\left.\mathrm{mg} \cdot \mathrm{L}^{-1}\right)$. Embryos were incubated in a growth chamber under 


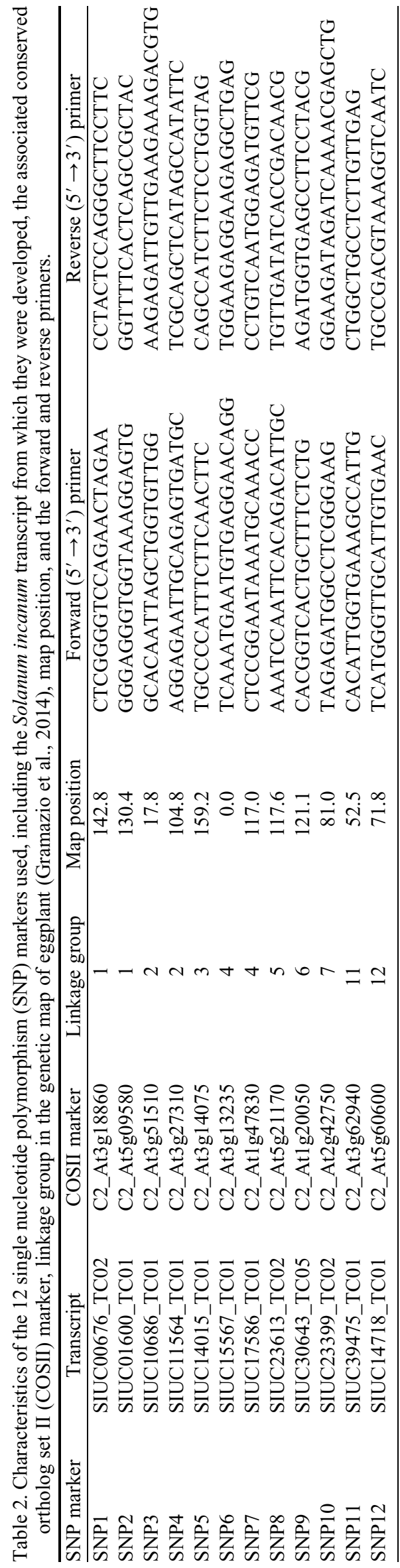

constant temperature $\left(25 \pm 1{ }^{\circ} \mathrm{C}\right)$ and a photoperiod of $16 / 8 \mathrm{~h}$ (light/dark). Seedlings from germinated embryos were transplanted in plastic pots containing growing substrate and covered with perforated plastic glasses for acclimatization.

Hybridity CONFIRMation. Confirmation of hybridity was performed on plantlets using one morphological trait (prickliness) and single nucleotide polypmorphism (SNP) molecular markers. For the prickliness characterization, young leaves $(\approx 10 \mathrm{~cm}$ long) of hybrid plants were evaluated using the Leaf prickles descriptor of EGGNET [European Network for Eggplant Genetic Resources (van der Weerden and Barendse, 2007)] using a 0 to 9 scale depending on the number of prickles in the upper surface of the leave $[0=$ none, $1=$ very few (1-2), $3=$ few (3-5), $5=$ several (6-10), $7=$ many $(11-20), 9=$ very many $(>20)]$. Prickliness of the hybrids plants was compared with young leaves of parents having the same stage of development.

For SNP genotyping genomic DNA was extracted from $75 \mathrm{mg}$ of young leaf tissue of the six S. melongena and 19 wild parental accessions and from interspecific hybrid plants using the cetyltrimethylammonium bromide method (Doyle and Doyle, 1987). DNA concentration was quantified, after electrophoresis on a $0.8 \%$ agarose gel, using a spectrophotometer (NanoDrop ND-1000; Thermo Fisher Scientific, Waltham, MA). DNA concentration was adjusted to 30 $\mathrm{ng} \cdot \mu \mathrm{L}^{-1}$. DNA quality was evaluated through the $260 / 280$ and 260/230 $\mathrm{nm}$ absorbance ratios.

Twelve SNP markers distributed through different linkage groups of the eggplant genetic map (Gramazio et al., 2014) were selected for genotyping the parentals and hybrids (Table 2) using the high-resolution melting technique (Wittwer et al., 2003). All polymerase chain reaction (PCR) reactions were performed in a thermocycler (LightCycler 480; Roche Applied Science, Mannheim, Germany). The PCR reaction mixture consisted of $2 \mu \mathrm{L}$ of genomic DNA (30 ng. $\left.\mu \mathrm{L}^{-1}\right), 0.25 \mu \mathrm{L}$ of forward and reverse primers $(10 \mu \mathrm{M}), 1 \mu \mathrm{L} \mathrm{MgCl}_{2}(25 \mathrm{~mm}$ ), $5 \mu \mathrm{L}$ Master Mix $2 \mathrm{X}$ (Roche Applied Science), and distilled water to a volume of $10 \mu \mathrm{L}$. After an initial denaturation step of $10 \mathrm{~min}$ at $95^{\circ} \mathrm{C}, 55 \mathrm{PCR}$ cycles were performed with $10 \mathrm{~s}$ of denaturation at $95^{\circ} \mathrm{C}$, $15 \mathrm{~s}$ for annealing at $55^{\circ} \mathrm{C}$, and $15 \mathrm{~s}$ for extension at $72^{\circ} \mathrm{C}$, followed by a melting cycle of $95^{\circ} \mathrm{C}$ for $1 \mathrm{~min}, 40^{\circ} \mathrm{C}$ for $1 \mathrm{~min}, 60^{\circ} \mathrm{C}$ for $1 \mathrm{~s}$, and a subsequent increase of temperature to $95^{\circ} \mathrm{C}$ at a rate of $0.1^{\circ} \mathrm{C} \cdot \mathrm{s}^{-1}$, keeping temperature at $95^{\circ} \mathrm{C}$ for $10 \mathrm{~s}$, and finally decreasing temperature to $40^{\circ} \mathrm{C}$ at a rate of $2.2{ }^{\circ} \mathrm{C} \cdot \mathrm{s}^{-1}$. Melting data were analyzed using the LightCycler 480 software (version 1.5, Roche Applied Science) using the "TM calling" analysis for verifying the lack of unspecific amplifications in the SNP and the "Gene scanning" analysis for checking the negative control and that melting curves were normalized through the "melt slider" and "threshold" parameters for an optimal differentiation of the genotypes. The pairwise number of homozygous SNP polymorphic among parents was calculated to detect SNP markers useful for the identification of heterozygous hybrids.

\section{Results}

INTERSPECIFIC HYBRIDIZATION AND FRUIT SET. A total of 1424 interspecific hybridizations were performed between the six S. melongena accessions and the 19 accessions of wild species (Table 3 ). Most of the hybridizations (81.1\%) 
were performed using S. melongena as female parent. Cultivated accessions presented considerable differences for flowering among the six cultivated $S$. melongena accessions. In this respect, some accessions like MEL1, MEL3, and MEL5 flowered profusely, whereas others like MEL4 and MEL6 produced few flowers. This resulted in important differences in the number of crosses that could be made with each of the $S$. melongena accessions, with differences of more than 3-fold in the number of hybridizations made between MEL1 and MEL4 (Table 3).

Fruit set was obtained in interspecific crosses between $S$. melongena and all wild species used, except with $S$. elaeagnifolium (Table 4). The percentage of fruit set of interspecific hybridizations was very variable depending on the direction of the hybridization and the wild species involved. In this respect, fruit set was generally higher in the wild species than in the cultivated $S$. melongena, with the exception of hybridizations involving $S$. dasyphyllum, $S$. violaceum, and $S$. torvum (Table 4 ). The highest rate of success in interspecific hybridizations when using $S$. melongena as female parent was obtained with the two species of the primary genepool (S. incanum and $S$. insanum) and with

Table 3. Number of interspecific hybridizations made with each of the Solanum melongena accessions as female and male parent (MEL1MEL3 from Ivory Coast, MEL4-MEL6 from Sri Lanka).

\begin{tabular}{lccr}
\hline Accession & Female $(+)$ & Male $(\widehat{)})$ & Total \\
\hline MEL1 & 295 & 49 & 344 \\
MEL2 & 173 & 30 & 203 \\
MEL3 & 284 & 86 & 370 \\
MEL4 & 91 & 12 & 103 \\
MEL5 & 236 & 53 & 289 \\
MEL6 & 76 & 39 & 115 \\
Total & 1155 & 269 & 1424 \\
\hline
\end{tabular}

secondary genepool species $S$. dasyphyllum and S. lichtenstenii, which presented a fruit set above $15 \%$. When using $S$. melongena as male parent, the highest fruit set was obtained again with the two primary genepool species and with the secondary genepool species $S$. anguivi, S. linnaeanum, and $S$. tomentosum, with values above $25 \%$ in the fruit set. A very low fruit set was obtained with secondary genepool species $S$. pyracanthos and $S$. violaceum and with the three tertiary genepool species, with the exception of hybridizations between $S$. melongena as male parent and $S$. sisymbrifolium as female parent, in which $11.4 \%$ of fruit set was obtained.

Some differences were observed among the $S$. melongena accessions in the fruit set percentage from the hybridizations with species of the three genepools. In general, the highest degree of success was obtained with species of the primary genepool, while the lowest with tertiary genepool species. For example, when using $S$. melongena as a female parent in hybridizations with wild species from the primary genepool, accession MEL6 presented a fruit set significantly higher than those of other accessions, like MEL1, MEL3, and MEL4 (Fig. 1). However, this same accession (MEL6) had the lowest fruit set percentage when used as a female in hybridizations with secondary genepool species. In this case, the highest values were obtained for MEL1 and MEL3. For hybridizations with the tertiary genepool, fruit set was only obtained with MEL1 as female parent (Fig. 1). When using S. melongena as male parent, the largest fruit set percentage in hybridizations with primary genepool species was obtained with MEL1, with values significantly higher than those of MEL3 and MEL4 (Fig. 1). Also, when hybridizations with secondary genepool species are concerned, the highest values were obtained for MEL1, with values significantly higher than those of MEL3, MEL5, and MEL6. Finally, for hybridizations with tertiary genepool species using $S$. melongena as a male, success was only obtained with accessions MEL2, MEL3, and MEL 5 (Fig. 1).

Table 4. Number of hybridizations, fruit set, seeds per fruit, and germination in interspecific hybridizations between Solanum melongena and wild relatives from the primary, secondary and tertiary genepools according to the direction of the hybridizations.

\begin{tabular}{|c|c|c|c|c|c|c|c|c|}
\hline \multirow[b]{2}{*}{ Wild relatives } & \multicolumn{4}{|c|}{ S. melongena (female parent) } & \multicolumn{4}{|c|}{ S. melongena (male parent) } \\
\hline & $\begin{array}{l}\text { Hybridizations } \\
\text { (no.) }\end{array}$ & $\begin{array}{c}\text { Fruit } \\
\text { set }(\%)\end{array}$ & $\begin{array}{c}\text { Seeds/fruit } \\
{[\text { mean } \pm \text { SE }(g)]}\end{array}$ & $\begin{array}{c}\text { Germination } \\
{[\text { mean } \pm \text { SE }(\%)]}\end{array}$ & $\begin{array}{l}\text { Hybridizations } \\
\text { (no.) }\end{array}$ & $\begin{array}{l}\text { Fruit } \\
\text { set }(\%)\end{array}$ & $\begin{array}{c}\text { Seeds/fruit } \\
{[\text { mean } \pm \text { SE }(\mathrm{g})]}\end{array}$ & $\begin{array}{c}\text { Germination } \\
{[\text { mean } \pm \text { SE }(\%)]}\end{array}$ \\
\hline \multicolumn{9}{|l|}{ Primary genepool } \\
\hline Solanum insanum & 175 & 17.8 & $2.67 \pm 0.51$ & $92.2 \pm 3.4$ & 51 & 33.3 & $2.18 \pm 0.32$ & $75.8 \pm 9.3$ \\
\hline \multicolumn{9}{|l|}{ Secondary genepool } \\
\hline Solanum anguivi & 68 & 14.7 & $0.68 \pm 0.16$ & $64.1 \pm 12.3$ & 32 & 34.4 & $0.21 \pm 0.04$ & $32.2 \pm 13.5$ \\
\hline Solanum lichtensteinii & 89 & 16.9 & $1.69 \pm 0.30$ & $54.9 \pm 12.0$ & 33 & 18.2 & $0.32 \pm 0.09$ & n.t. ${ }^{y}$ \\
\hline Solanum linnaeanum & 106 & 8.5 & $0.53 \pm 0.09$ & $0.0 \pm 0.0$ & 21 & 47.6 & $0.42 \pm 0.06$ & $66.7 \pm 9.8$ \\
\hline Solanum pyracanthos & 179 & 0.0 & - & - & 19 & 5.3 & $0.11^{\mathrm{z}}$ & $7.7^{\mathrm{z}}$ \\
\hline Solanum tomentosum & 34 & 11.8 & $0.18 \pm 0.08$ & $40.0 \pm 28.3$ & 25 & 32.0 & $0.11 \pm 0.02$ & $0.0 \pm 0.0$ \\
\hline Solanum violaceum & 21 & 4.8 & $0.09^{z}$ & $25.0^{\mathrm{w}}$ & 11 & 0.0 & - & - \\
\hline \multicolumn{9}{|l|}{ Tertiary genepool } \\
\hline
\end{tabular}

${ }^{\mathrm{z}}$ No SE is given as only one fruit was obtained.

${ }^{\mathrm{y}}$ Not tested.

${ }^{\mathrm{x}}$ Fruit were parthenocarpic.

${ }^{\text {w}}$ Fruit were harvested when immature to extract developing embryos. 

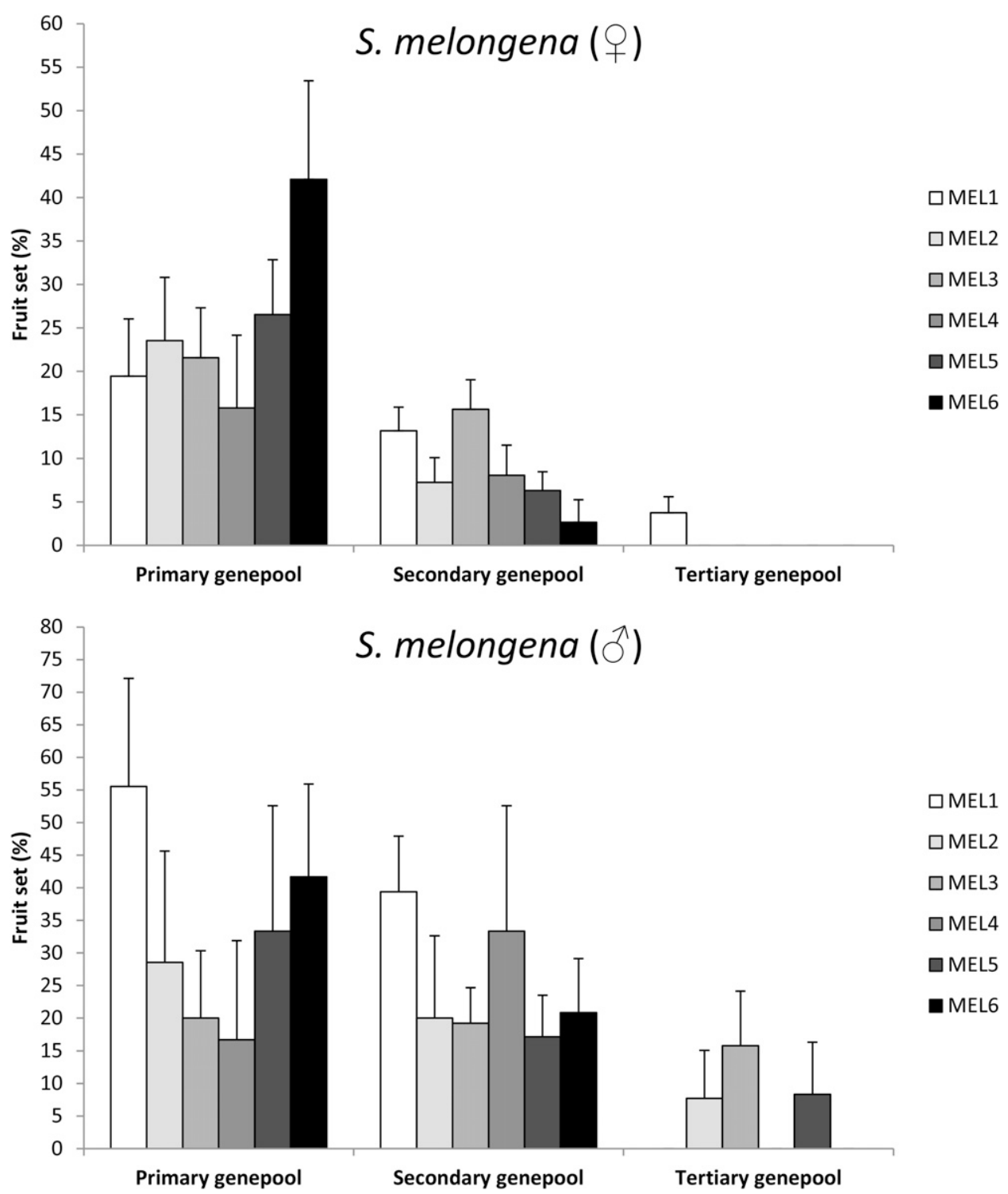

Fig. 1. Fruit set percentage $( \pm \mathrm{SE})$ for each of the six Solanum melongena accessions used in interspecific hybridization with wild relatives from the primary, secondary, and tertiary pools when using $S$. melongena as female (above) or male (below). All fruit obtained with tertiary genepool wild relatives when using $S$. melongena as a male were parthenocarpic.

SeEd QUANTITY Per FRUIT. When using S. melongena as a female parent, the largest amount of seeds per fruit was obtained in hybridizations with $S$. insanum, with an average value above $2.5 \mathrm{~g} /$ fruit (Table 4 ), which is equivalent to more than 500 seeds/fruit, as the weight of 100 seeds of $S$. melongena is around $0.4-0.5 \mathrm{~g}$. This was followed by hybridizations with the other primary genepool species ( $S$. incanum) and with secondary genepool species $S$. dasyphyllum and $S$. lichtenstenii, which had more than $1 \mathrm{~g}$ of seeds per fruit. The lowest amounts of seeds per fruit were obtained with $S$. tomentosum $(<0.2 \mathrm{~g} /$ fruit) and $S$. violaceum ( $<0.1 \mathrm{~g} /$ fruit). An average of 3.75 embryos/fruit could be rescued from immature fruit resulting from hybridizations between $S$. melongena as a female and $S$. torvum as a male. Regarding hybridizations involving $S$. melongena as a male parent, the highest amounts of seeds per fruit were obtained with the two primary genepool species, with average values above $1.5 \mathrm{~g}$ of seed per fruit (Table 4). Among the secondary genepool species that set fruit when $S$. melongena was used as a male parent, the highest amount of seeds was obtained in hybridizations with $S$. dasyphyllum $(0.78 \mathrm{~g} /$ fruit $)$, with values more than 7-fold higher than $S$. pyracanthos and $S$. tomentosum, which were the species with the lowest amount of seeds per fruit (Table 4). No viable embryos were found in the hybridizations of $S$. melongena as a male parent with $S$. sisymbrifolium, which was the only tertiary genepool species to set fruit when using $S$. melongena as a male.

As a result of the hybridizations made, seed (or viable embryos in the case of hybrids with $S$. torvum) was obtained for 58 interspecific hybrid combinations involving the six $S$. melongena accessions and the 19 accessions of the wild species (Table 5). For primary genepool species $S$. incanum and $S$. insanum and for secondary genepool species $S$. anguivi, S. dasyphyllum, S. lichtenstenii, S. linnaeanum, and S. tomentosum, hybrid seed could be obtained with all or most of the $S$. melongena accessions, either using $S$. melongena as female, as male, or both (Table 5). For S. pyracanthos, S. violaceum, and S. torvum, hybrid seed (embryos in the case of $S$. torvum) could only be obtained with $S$. melongena accession MEL1. In consequence, the accession with the greatest number of hybrid combinations for which seed could be obtained was MEL1, with a total of 16 hybrid combinations (of which 12 was acting as female parent and nine as male). For the rest of accessions we obtained between 7 (MEL2) and 10 (MEL3) hybrid combinations (Table 5). Of these, very few hybrid combinations (3) could be obtained using MEL6 as female parent, while the accession for which the largest number of combinations (10) could be obtained acting as a male was with accession MEL3 (Table 5).

SEED Germination. The highest seed germination when using $S$. melongena as a female parent was obtained for hybrids with primary genepool species $S$. insanum, with average values above $90 \%$ (Table 4). Intermediate average values, between $40 \%$ and $65 \%$, were obtained with $S$. incanum and with secondary genepool species $S$. anguivi, S. lichtenstenii, $S$. tomentosum, S. dasyphyllum, and $S$. violaceum presented average values below $30 \%$, while no germination was obtained for hybrids with $S$. linnaeanum (Table 4). Regarding hybrids using tertiary genepool species $S$. torvum as male parent, $80 \%$ of the rescued embryos were viable and developed into plantlets that could be successfully acclimatized. 
When S. melongena was used as a male parent, the highest germination was obtained for hybrids with the two primary genepool species $(S$. incanum and $S$. insanum). When considering secondary genepool species, the highest germination was obtained in hybrids with S. linnaeanum $(>65 \%)$, whereas the lowest in hybrids with $S$. tomentosum, in which no germination was observed.

Hybridity CONFIRMATION. For the morphological confirmation of hybridity, all plantlets of the $S$. melongena parents were nonprickly, i.e., they had a value of 0 in the prickliness scale. A wide range of prickliness was found among wild relatives, with a range from 0 [one nonprickly accession of $S$. insanum (INS2), S. anguivi, and $S$. tomentosum] to 9 ( $S$. dasyphyllum and $S$. pyracanthos) (Table 6). Except for $S$. insanum, in which considerable variation was found among accessions for prickliness, with one nonprickly accession and two prickly accessions, little variation was found among accessions of a given species (Table 6). No differences were found among reciprocal hybrids for prickliness and therefore no differentiation was made among both types of hybrids. Prickliness was dominant or overdominant and all interspecific hybrids between $S$. melongena and wild species, except those with $S$. anguivi, were prickly (Fig. 2). In this respect, it is remarkable that hybrids of $S$. melongena with two nonprickly accessions ( $S$. insanum INS2 and the single $S$. tomentosum accession) were prickly, in particular in the case of hybrids with $S$. tomentosum (Table 6).

The $S$. melongena accessions presented the same SNP fingerprint for all markers except for SNP3, in which MEL1, MEL2, and MEL6 presented one allele $(G)$ and MEL3, MEL4, and MEL5 presented another allele (A). This resulted in two profiles for $S$. melongena, which we named, respectively, profile 1 and 2. The number of polymorphic SNPs between $S$. melongena and the wild species evaluated ranged between 0 and 10 (Table 7). The accessions with a lower number of polymorphisms were those of the primary genepool species $S$. insanum (0 to 1), while the largest number has been found with the tertiary genepool species S. sisymbriifolium (10). Amazingly, secondary genepool S. lichtensteinii LIC2 and $S$. linnaeanum LIN1 presented a lower number of polymorphic loci with $S$. melongena than the single accession of the primary genepool species $S$. incanum (Table 7). Also, S. torvum was the tertiary genepool species with lowest number of polymorphic loci with $S$. melongena (6).

\section{Discussion}

This is the first comprehensive study of interspecific hybridization between eggplant and a large number of wild
Table 6. Prickliness (0-9 scale) of young leaves $(\approx 10 \mathrm{~cm}$ leaf blade length) of eggplant wild relatives and of hybrid plantlets between Solanum melongena and the wild species. Large differences were observed among accessions of Solanum insanum and were divided in prickly (INS1 and INS3) and nonprickly (INS2) accessions. Cultivated $S$. melongena parents were always nonprickly ( 0 value).

\begin{tabular}{lcc}
\hline Wild parent accessions & $\begin{array}{c}\text { Prickliness } \\
\text { wild parent } \\
(0-9 \text { scale })^{z}\end{array}$ & $\begin{array}{c}\text { Prickliness } \\
\text { interspecific } \\
\text { hybrids (0-9 scale) }\end{array}$ \\
\hline Solanum incanum & $1-3$ & $3-5$ \\
S. insanum (prickly) & $5-7$ & $5-7$ \\
S. insanum (nonprickly) & 0 & 1 \\
Solanum anguivi & 0 & 0 \\
Solanum dasyphyllum & 9 & 9 \\
Solanum lichtensteinii & $0-1$ & $1-3$ \\
Solanum linnaeanum & $5-7$ & 7 \\
Solanum pyracanthos & 9 & 9 \\
Solanum tomentosum & 0 & 5 \\
Solanum violaceum & 7 & 7 \\
Solanum torvum & $3-5$ & 5
\end{tabular}

${ }^{\mathrm{z}} 0=$ none, $1=$ very few $(1-2), 3=$ few $(3-5), 5=$ several $(6-10)$, $7=$ many $(11-20), 9=$ very many $(>20)$.

relatives in which different types of quantitative data related to the efficiency of interspecific hybridization have been obtained and have been complemented with hybridity confirmation using morphological and molecular markers. Our results 


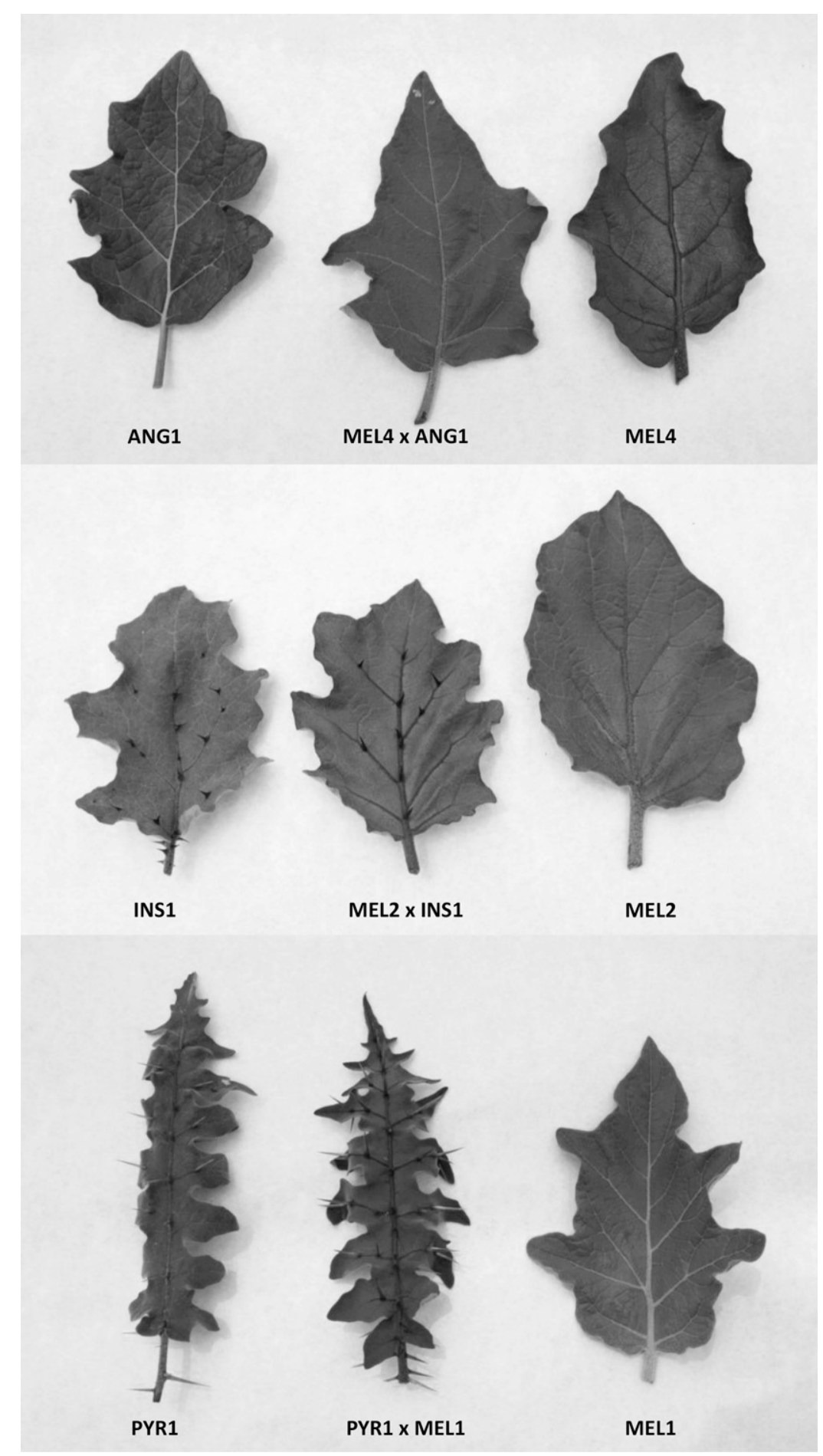

Fig. 2. Leaves of wild eggplant relatives showing different degrees of prickliness (Solanum anguivi ANG1, above; $S$. insanum INS1, center; and $S$. pyracanthos PYR1, below), cultivated eggplant (MEL codes), and their respective interspecific hybrids.

confirm that cultivated eggplant is amenable to interspecific hybridization (Daunay and Hazra, 2012; Rotino et al., 2014), as hybrids could be obtained between $S$. melongena and all the wild species from the primary and secondary genepools as well as with $S$. torvum, which is a New World species from the tertiary genepool (Daunay and Hazra, 2012; Whalen, 1984). Given the large genetic diversity present in these wild species, compared with the cultivated S. melongena (Mutegi et al., 2015; Vorontsova et al., 2013; Weese and Bohs, 2010), our results indicate that there are ample prospects for broadening the narrow genetic base of eggplant (MuñozFalcón et al., 2009) and for obtaining interspecific hybrids for use as rootstocks (Gisbert et al., 2011b).

Interspecific hybridization with the two primary genepool species has been highly efficient, which facilitates introgression breeding or the commercial production of $F_{1}$ hybrid seed for use as rootstocks. In this respect, hybrids between $S$. incanum and $S$. melongena are highly vigorous and have been proposed as rootstocks for the commercial production of eggplant (Gisbert et al., 2011b). Also, given that $S$. insanum is harvested from the wild and occasionally cultivated in Southeast Asia (Davidar et al., 2015), hybrids between both species may have a commercial interest.

The success of interspecific hybridization, seed production, and germination of secondary genepool species has been very variable and depended on the direction of the cross. In this respect, given the high success of hybridization with some secondary genepool species, like $S$. anguivi, S. dasyphyllum, or S. lichteinsteinii, its transfer to the primary genepool might be considered if hybrids and subsequent generations are fully fertile (Harlan and de Wet, 1971). Differences in the hybridization success may also be due to differences in the ploidy level between the diploid S. melongena and some of the wild species. In this respect, polyploidy has been described in some of the species used, like $S$. elaeagnifolium (Scaldaferro et al., 2012). Although on average the fruit set of interspecific hybridizations has been higher in wild species compared with $S$. melongena, in general more seeds have been obtained when using the latter as maternal parent, probably because it has more ovules per fruit than wild species (Isshiki and Kawajiri, 2002). This indicates that, generally, a higher efficiency in seed production will be obtained when using $S$. melongena as a maternal parent. Interesting features can be found among secondary genepool species with a greater degree of success in interspecific hybridization, like resistance to Ralstonia solanacearum in S. anguivi (Schippers, 2000), high content in bioactive phenolic acids in $S$. dasyphyllum (Plazas et al., 2014b), drought tolerance in $S$. lichtensteinii (Vorontsova and Knapp, 2012), or tolerance to salinity and resistance to verticillium wilt (Verticillium dahliae) and Leveillula taurica in S. linnaeanum (Bubici and Cirulli, 2008; Daunay et al., 1991; Liu et al., 2015). No germination was obtained in the hybrids with $S$. linnaeanum when using $S$. melongena as maternal parent, whereas good germination was 
Table 7. Number of single nucleotide polymorphism markers out of 12 tested that differentiate the two profiles of Solanum melongena (Profile 1: accessions MEL1, MEL2, and MEL6; Profile 2: accessions MEL3, MEL4, and MEL5) from wild relatives of the primary, secondary, and tertiary genepools.

\begin{tabular}{lcc}
\hline & \multicolumn{2}{c}{ S. melongena accessions } \\
\cline { 2 - 3 } Wild relatives & $\begin{array}{c}\text { Profile 1 (MEL1, } \\
\text { accessions }\end{array}$ & $\begin{array}{c}\text { Profile 2 (MEL3, } \\
\text { MEL4, MEL5) }\end{array}$ \\
\hline Primary genepool & 4 & 3 \\
INC1 & 1 & 0 \\
INS1 & 1 & 0 \\
INS2 & 1 & 0 \\
INS3 & & \\
Secondary genepool & 9 & 8 \\
ANG1 & 8 & 7 \\
ANG2 & 6 & 5 \\
DAS1 & 4 & 3 \\
LIC1 & 1 & 2 \\
LIC2 & 1 & 2 \\
LIN1 & 2 & 1 \\
LIN3 & 6 & 5 \\
PYR1 & 4 & 3 \\
TOM1 & 5 & 4 \\
VIO1 & 9 & 8 \\
Tertiary genepool & 10 & 10 \\
ELE1 & 9 & 6 \\
SIS1 & 6 & 6 \\
SIS2 & 6 & \\
TOR2 & & \\
TOR3 & & \\
\hline
\end{tabular}

obtained in the reciprocal cross. Other researchers have also reported the use of $S$. linnaeanum as maternal parent to obtain interspecific hybrid plants with $S$. melongena (Acciarri et al., 2007; Doganlar et al., 2002; Liu et al., 2015). It remains to be investigated if this phenomenon is due to embryo or endosperm failure in specific hybrid combinations, as it has been found in other eggplant crosses (Lester and Kang, 1998), or due to other causes. Therefore, we recommend using $S$. linnaeanum as a female parent in interspecific hybridizations with eggplant. Solanum pyracanthos is the most phylogenetically distant species of all the secondary genepool species tested (Vorontsova et al., 2013) and up to now no interspecific hybrid plantlets had been obtained with this species (Daunay and Hazra, 2012; Rotino et al., 2014). This is evidence that artificial sexual hybrids of eggplant with some phylogenetically distant Old World species of Solanum section Leptostemonum can be obtained without needing embryo rescue and expands the range of species for which interspecific hybrids with eggplant can be obtained.

We have confirmed the feasibility of obtaining sexual interspecific hybrids between S. melongena and the New World tertiary genepool species $S$. torvum (Daunay and Hazra, 2012; Kumchai et al., 2013; Rotino et al., 2014) using the former as maternal parent, although a low success was obtained in the fruit set percentage, and embryo rescue was needed. However, these interspecific hybrids are highly sterile (Kumchai et al., 2013), which may be difficult to backcross to S. melongena. In this respect, Toppino et al. (2008) found that tetraploid amphidiploids between $S$. aethiopicum and S. melongena could be backcrossed to tetraploid S. melongena and after subsequent anther culture to recover diploid individuals, could be used for introgression of the resistance to fusarium wilt (Fusarium oxysporum f. sp. melongena) from S. aethiopicum to $S$. melongena. Also, the use of different $S$. melongena genotypes or bridge species for hybridization with these interspecific hybrids combined with embryo rescue may help in introgressing traits of interest from $S$. torvum into the genetic background of S. melongena. On the other side, no hybrids were obtained with S. sisymbriifolium and S. elaeagnifolium, confirming that both species are very distant from eggplant and in the case of $S$. elaeagnifolium may also present differences with $S$. melongena in ploidy level (Scaldaferro et al., 2012; Vorontsova et al., 2013). Differences among genotypes of a given species may be important in obtaining interspecific hybrids of eggplant (Behera and Singh, 2002; Bletsos et al., 1998; Devi et al., 2015; Kumchai et al., 2013; Lester and Kang, 1998). In our case, we have found that some accessions are better than others for obtaining interspecific hybrids. In this respect, accession MEL1 has proved as the best one for interspecific hybridization. This suggests that this accession could be used as a recurrent parent for introgression breeding in eggplant or for acting as a bridge for introgression in other $S$. melongena materials (Liedl and Anderson, 1993).

Confirmation of hybridity was obtained with both morphological and molecular markers. Prickliness is a dominant trait in eggplant (Doganlar et al., 2002; Prohens et al., 2013) and given that all $S$. melongena accessions were nonprickly, interspecific hybrids in which the wild parent is prickly were also prickly, which allowed confirming hybridity in crosses when $S$. melongena is used as a female parent. However, we have found some cases of overdominance, with a greater prickliness in the hybrid than in the wild parent and even prickly hybrids when using nonprickly wild parents, like $S$. tomentosum. This phenomenon has already been described in interspecific hybrids of eggplant with nonprickly cultivated $S$. aethiopicum and S. macrocarpon (Devi et al., 2015; Lester, 1986; Prohens et al., 2012; Schaff et al., 1982), indicating complementarity between the genes for prickliness between the two nonprickly parents. This has important implications for eggplant breeding, in which lack of prickles is a desired trait (Daunay and Hazra, 2012).

SNP markers have also proved useful for confirmation of hybridity, as with a limited number of SNPs, polymorphism was found between $S$. melongena and all the wild species evaluated. SNPs or alternative codominant markers, like simple sequence repeats (SSRs) (Vilanova et al., 2014), can be used for confirmation of hybridity before prickliness can be scored and in cases like in hybrids with $S$. anguivi, in which prickliness is not a diagnostic trait for hybrid identification. Furthermore, given that many SNPs and SSRs are available in eggplant (Barchi et al., 2011; Hirakawa et al., 2014; Vilanova et al., 2012), marker-assisted selection breeding, based on molecular markers, and combined with phenotyping, will allow the efficient selection of materials with introgressed desirable genes from the wild species without unfavorable traits, as well as to obtain collections of introgression lines (Collard and Mackill, 2008). The number of differences in SNP markers generally confirms the taxonomic relationships previously established (Knapp et al., 2013; Vorontsova et al., 2013; Weese and Bohs, 2010). However, the greater number of SNP differences in secondary genepool $S$. anguivi compared with tertiary genepool S. torvum was unexpected. However, the number of SNP was 
limited and a larger number of SNP markers would be needed for phylogenetic studies in eggplant and wild relatives.

In summary, eggplant can be hybridized with many wild relatives, including the phylogenetically distant $S$. torvum. The degree of success in obtaining hybrids depends on the wild species and $S$. melongena accessions involved and on the direction of the hybridization. In this respect, we have found that using selected $S$. melongena accessions as a female parent, like MEL1, which are very prolific and gives hybrid with many wild species will facilitate the exploitation of crop wild relatives for eggplant breeding. Also, we have found that production of large amounts of interspecific hybrid seed is possible, which may be of interest for the commercial production of rootstocks. The results obtained may also have implications for the establishment of taxonomic relationships and genepool assignments in this group of species. Ultimately, our results will contribute to the enhancement of wild relatives, which may play a major role in adapting to climate change, for eggplant breeding.

\section{Literature Cited}

Acciarri, N., E. Sabatini, S. Voltattorni, T. Ciriaci, G. Tamietti, D. Valentino, G. Mennella, F. Cavallanti, M.G. Tacconi, L. Toppino, G. Grazioli, R. Pedretti, P. Alberti, and G.L. Rotino. 2007. First eggplant pure lines of different typologies derived from sexual and somatic hybridization with $S$. sodomaeum and $S$. aethiopicum gr. aculeatum and gr. gilo, p. 327-338. In: K. Niemirowicz-Szczytt (ed.). Progress in research on Capsicum \& eggplant. Warsaw Univ. Life Sci. Press, Warsaw, Poland.

Barchi, L., S. Lanteri, E. Portis, A. Acquadro, G. Valè, L. Toppino, and G.L. Rotino. 2011. Identification of SNP and SSR markers in eggplant using RAD tag sequencing. BMC Genomics 12:304.

Behera, T.K. and N. Singh. 2002. Inter-specific crosses between eggplant (Solanum melongena L.) with related Solanum species. Sci. Hort. 95:165-172.

Bletsos, F.A., D.G. Roupakias, M.L. Tsaktsira, A.B. Scaltsoyjannes, and C.C. Thanassoulopoulos. 1998. Interspecific hybrids between three eggplant (Solanum melongena L.) cultivars and two wild species (Solanum torvum Sw. and Solanum sisymbriifolium Lam.). Plant Breed. 117:159-164.

Bletsos, F.A., C.C. Thanassoulopoulos, and D.G. Roupakias. 2003. Effect of grafting on growth, yield and verticillium wilt of eggplant. HortScience 38:183-186.

Bubici, G. and M. Cirulli. 2008. Screening and selection of eggplant and wild related species for resistance to Leveillula taurica. Euphytica 164:339-345.

Cericola, F., E. Portis, L. Toppino, L. Barchi, N. Acciarri, T. Ciriaci, T. Sala, G.L. Rotino, and S. Lanteri. 2013. The population structure and diversity of eggplant from Asia and the Mediterranean Basin. PLoS One 8:e73702.

Christodoulakis, N.S., P.N. Lampri, and C. Fasseas. 2009. Structural and cytochemical investigation of the silverleaf nightshade (Solanum elaeagnifolium), a drought-resistant alien weed of the Greek flora. Austral. J. Bot. 57:432-438.

Collard, B.C.Y. and D.J. Mackill. 2008. Marker-assisted selection: An approach for precision plant breeding in the twenty-first century. Phil. Trans. Royal Soc. B 363:557-572.

Daunay, M.C. and P. Hazra. 2012Eggplant, p. 257-322. In: K.V. Peter and P. Hazra (eds.). Handbook of vegetables. Studium Press, Houston, TX

Daunay, M.C., R.N. Lester, and H. Laterrot. 1991The use of wild species for the genetic improvement of brinjal-eggplant (Solanum melongena) and tomato (Lycopersicon esculentum), p. 389-413. In: J.C. Hawkes, R.N. Lester, M. Nee, and N. Estrada (eds.). Solanaceae III, taxonomy, chemistry, evolution. Royal Botanic Gardens Kew and Linnean Soc., London, UK.
Davidar, P., A.A. Snow, M. Rajkumar, R. Pasquet, M.C. Daunay, and E. Mutegi. 2015. The potential for crop to wild hybridization in eggplant (Solanum melongena; Solanaceae) in southern India. Amer. J. Bot. 102:129-139.

Dempewolf, H., R.H. Eastwood, L. Guarino, C.K. Khoury, J.V. Müller, and J. Toll. 2014. Adapting agriculture to climate change: A global initiative to collect, conserve, and use crop wild relatives. Agroecol. Sustainable Food Systems 38:369-377.

Devi, C.P., A.D. Munshi, T.K. Behera, H. Choudhary, Vinod, B. Gurung, and P. Saha. 2015. Cross compatibility in interspecific hybridization of eggplant, Solanum melongena, with its wild relatives. Sci. Hort. 193:353-358.

Díez, M.J. and F. Nuez. 2008. Tomato, p. 249-323. In: J. Prohens and F. Nuez (eds.). Handbook of plant breeding: Vegetables II. Springer, New York, NY.

Doganlar, S., A. Frary, M.C. Daunay, R.N. Lester, and S. Tanksley. 2002. A comparative linkage map of eggplant (Solanum melongena) and its implications for genome evolution on the Solanaceae. Genetics 161:1697-1711.

Doyle, J.J. and J.L. Doyle. 1987. A rapid DNA isolation procedure for small quantities of fresh leaf tissue. Phytochem. Bul. 19:11-15.

Food and Agriculture Organization of the United Nations. 2015FAOSTAT production databases. 3 Aug. 2015. $<$ http://www.faostat3.fao. org $>$.

Fowler, C., G. Moore, and G.C. Hawtin. 2003. The International Treaty on Plant Genetic Resources for Food and Agriculture: A primer for the Future Harvest Centres of the CGIAR. Intl. Plant Genet. Resources Inst., Rome, Italy.

Gisbert, C., J. Prohens, and F. Nuez. 2011a. Treatments for improving seed germination in eggplant and related species. Acta Hort. 898: 45-51.

Gisbert, C., J. Prohens, M.D. Raigón, J.R. Stommel, and F. Nuez. 2011b. Eggplant relatives as sources of variation for developing new rootstocks: Effects of grafting on eggplant yield and fruit apparent quality and composition. Sci. Hort. 128:14-22.

Gousset, C., C. Collonnier, K. Mulya, I. Mariska, G.L. Rotino, P. Besse, A. Servaes, and D. Sihachakr. 2005. Solanum torvum, as a useful source of resistance against bacterial and fungal diseases for improvement of eggplant (S. melongena L.). Plant Sci. 168:319-327.

Gramazio, P., J. Prohens, M. Plazas, I. Andújar, F.J. Herraiz, E. Castillo, S. Knapp, R.S. Meyer, and S. Vilanova. 2014. Location of chlorogenic acid biosynthesis pathway and polyphenol oxidase genes in a new interspecific anchored linkage map of eggplant. BMC Plant Biol. 14:350.

Hajjar, R. and T. Hodgkin. 2007. The use of wild relatives in crop improvement: A survey of developments over the last 20 years. Euphytica 156:1-13.

Harlan, J.R. and J.M.J. de Wet. 1971. Toward a rational classification of cultivated plants. Taxon 20:509-517.

Hirakawa, H., K. Shirasawa, K. Miyatake, T. Nunome, S. Negoro, A. Ohyama, H. Yamaguchi, S. Sato, S. Isobe, S. Tabata, and H. Fukuoka. 2014. Draft genome sequence of eggplant (Solanum melongena L.): The representative Solanum species indigenous to the Old Word. DNA Res. 21:649-660.

Isshiki, S. and N. Kawajiri. 2002. Effect of cytoplasm of Solanum violaceum Ort. on fertility of eggplant (S. melongena L.). Sci. Hort. 93:9-18.

Khan, M.M.R. and S. Isshiki. 2011. Development of a cytoplasmic male-sterile line of eggplant (Solanum melongena L.) with the cytoplasm of Solanum anguivi. Plant Breed. 130:256-260.

Knapp, S., M.S. Vorontsova, and J. Prohens. 2013. Wild relatives of the eggplant (Solanum melongena L.: Solanaceae): New understanding of species names in a complex group. PLoS One 8:e57039.

Kumchai, J., Y.C. Wei, C.Y. Lee, F.C. Chen, and S.W. Chin. 2013. Production of interspecific hybrids between commercial cultivars of the eggplant (Solanum melongena L.) and its wild relative S. torvum. Genet. Mol. Res. 12:755-764. 
Lester, R.N. 1986. Taxonomy of scarlet eggplants, Solanum aethiopicum L. Acta Hort. 182:125-132.

Lester, R.N., P.M.L. Jaeger, and A. Child. 2011. Solanum in Africa. Celia Lester, Birmingham, UK.

Lester, R.N. and J.H. Kang. 1998. Embryo and endosperm failure in Solanum species and hybrids. Ann. Bot. (Lond.) 82:445-453.

Liedl, B.E. and N.O. Anderson. 1993. Reproductive barriers: Identification, uses, and circumvention. Plant Breed. Rev. 11:675-681.

Liu, J., Z. Zheng, X. Zhou, C. Feng, and Y. Zhuang. 2015. Improving the resistance of eggplant (Solanum melongena) to verticillium wilt using wild species Solanum linnaeanum. Euphytica 201:463-469.

Manzur, J.P., C. Penella, and A. Rodríguez-Burruezo. 2013. Effect of the genotype, developmental stage and medium composition on the in vitro culture efficiency of immature zygotic embryos from genus Capsicum. Sci. Hort. 161:181-187.

Meyer, R.S., K.G. Karol, D.P. Little, and M.H. Nee. 2012. Phylogeographic relationships among Asian eggplants and new perspectives on eggplant domestication. Mol. Phylogenet. Evol. 63:685-701.

Morgan, E.R., G.M. Timmermann-Vaughan, A.J. Conner, W.B. Griffing, and R. Pickering. 2010. Plant interspecific hybridization: Outcomes and issues at the intersection of species. Plant Breed. Rev. 34:161-220.

Muñoz-Falcón, J.E., J. Prohens, S. Vilanova, and F. Nuez. 2009. Diversity in commercial varieties and landraces of black eggplants and implications for broadening the breeders' genepool. Ann. Appl. Biol. 154:453-465.

Mutegi, E., A.A. Snow, M. Rajkumar, R. Pasquet, H. Ponniah, M.C. Daunay, and P. Davidar. 2015. Genetic diversity and population structure of wild/weedy eggplant (Solanum insanum; Solanaceae) in southern India: Implications for conservation. Amer. J. Bot. 102:140-148.

Plazas, M., I. Andújar, S. Vilanova, P. Gramazio, F.J. Herraiz, and J. Prohens. 2014a. Conventional and phenomics characterization provides insight into the diversity and relationships of hypervariable scarlet (Solanum aethiopicum L.) and gboma (S. macrocarpon L.) eggplant complexes. Front. Plant Sci. 5:318.

Plazas, M., J. Prohens, A.N. Cuñat, S. Vilanova, P. Gramazio, F.J. Herraiz, and I. Andújar. 2014b. Reducing capacity, chlorogenic acid content and biological activity in a collection of scarlet (Solanum aethiopicum) and gboma (S. macrocarpon) eggplants. Intl. J. Mol. Sci. 15:17221-17241.

Prohens, J., G.J. Anderson, F.J. Herraiz, G. Bernardello, A. SantosGuerra, D. Crawford, and F. Nuez. 2007. Genetic diversity and conservation of two endangered eggplant relatives (Solanum vespertilio Aiton and Solanum lidii Sunding) endemic to the Canary Islands. Genet. Resources Crop Evol. 54:451-464.

Prohens, J., M. Plazas, M.D. Raigón, J.M. Seguí-Simarro, J.R. Stommel, and S. Vilanova. 2012. Characterization of interspecific hybrids and first backcross generations from crosses between two cultivated eggplants (Solanum melongena and S. aethiopicum
Kumba group) and implications for eggplant breeding. Euphytica 186:517-538.

Prohens, J., B.D. Whitaker, M. Plazas, S. Vilanova, M. Hurtado, M. Blasco, P. Gramazio, and J.R. Stommel. 2013. Genetic diversity in morphological characters and phenolic acids content resulting from an interspecific cross between eggplant (Solanum melongena) and its wild ancestor (S. incanum). Ann. Appl. Biol. 162:242-257.

Rotino, G.L., T. Sala, and L. Toppino. 2014. Eggplant, p. 381-409. In: A. Pratap and J. Kumar (eds.). Alien gene transfer in crop plants. Volume 2. Springer, New York, NY.

Scaldaferro, M., F. Chiarini, F.F. Santiñaque, G. Bernardello, and E.A. Moscone. 2012. Geographic pattern and ploidy levels of the weed Solanum elaeagnifolium (Solanaceae) from Argentina. Genet. Resources Crop Evol. 59:1833-1847.

Schaff, D.A., G. Jelenkovic, C.D. Boyer, and B.L. Pollack. 1982. Hybridization and fertility of hybrid derivatives of Solanum melongena L. and Solanum macrocarpon L. Theor. Appl. Genet. 62:149153.

Schippers, R.R. 2000. African indigenous vegetables: An overview of the cultivated species. Natural Resources Inst./ACP-EU Tech. Ctr. Agr. Rural Cooperation, Chatham, UK.

Toppino, L., G. Valè, and G.L. Rotino. 2008. Inheritance of Fusarium wilt resistance introgressed from Solanum aethiopicum Gilo and Aculeatum groups into cultivated eggplant ( $S$. melongena) and development of associated PCR-based. Mol. Breed. 22:237-250.

van der Weerden, G.M. and G.W.M. Barendse. 2007. A web-searchable database developed for the EGGNET project and applied to the Radboud University Solanaceae database. Acta Hort. 745:503-506.

Vilanova, S., M. Hurtado, A. Cardona, M. Plazas, P. Gramazio, F.J. Herraiz, I. Andújar, and J. Prohens. 2014. Genetic diversity and relationships in local varieties of eggplant from different cultivar groups as assessed by genomic SSR markers. Notulae Botanicae Horti Agrobotanici Cluj-Napoca 42:59-65.

Vilanova, S., J.P. Manzur, and J. Prohens. 2012. Development and characterization of genomic simple sequence repeat markers in eggplant and their application to the study of diversity and relationships in a collection of different cultivar types and origins. Mol. Breed. 30:647-660.

Vorontsova, M.S. and S. Knapp. 2012Solanum section Melongena, p. 198-215. In: H. Beentje (ed.). Flora of tropical East Africa. Royal Botanic Gardens, Kew, UK.

Vorontsova, M.S., S. Stern, L. Bohs, and S. Knapp. 2013. African spiny Solanum (subgenus Leptostemonum, Solanaceae): A thorny phylogenetic tangle. Bot. J. Linn. Soc. 173:176-193.

Weese, T.L. and L. Bohs. 2010. Eggplant origins: Out of Africa, into the Orient. Taxon 59:49-56.

Whalen, M.D. 1984. Conspectus of species groups in Solanum subgenus Leptostemonum. Gentes Herbarum 12:179-282.

Wittwer, C.T., G.H. Reed, C.N. Gundry, J.G. Vandersteen, and R.J. Pryor. 2003. High-resolution genotyping by amplicon melting analysis using LCGreen. Clin. Chem. 49:853-860. 